NBER WORKING PAPER SERIES

\title{
PRENATAL DRUG USE AND THE PRODUCTION OF INFANT HEALTH
}

\author{
Kelly Noonan \\ Nancy Reichman \\ Hope Corman \\ Dhaval Dave \\ Working Paper 11433 \\ http://www.nber.org/papers/w11433 \\ NATIONAL BUREAU OF ECONOMIC RESEARCH \\ 1050 Massachusetts Avenue \\ Cambridge, MA 02138 \\ June 2005
}

\begin{abstract}
This paper was presented at the annual meeting of The Population Association of America, Philadelphia, PA, March 31-April 2, 2005. The research was supported by Grants \#R01-HD- 45630 and \#R01-HD-35301 from the National Institute of Child Health and Human Development. We are grateful for valuable input from Justin DePrince, William Greene, Michael Grossman, Robert Kaestner, Magdalena Ostatkiewicz, Laura Penrose, Ofira Schwartz-Soicher, and Judith Shinogle. The views expressed herein are those of the author(s) and do not necessarily reflect the views of the National Bureau of Economic Research.
\end{abstract}

(C2005 by Kelly Noonan, Nancy Reichman, Hope Corman, and Dhaval Dave. All rights reserved. Short sections of text, not to exceed two paragraphs, may be quoted without explicit permission provided that full credit, including (C) notice, is given to the source. 
Prenatal Drug Use and the Production of Infant Health

Kelly Noonan, Nancy Reichman, Hope Corman, and Dhaval Dave

NBER Working Paper No. 11433

June 2005

JEL No. I12

\begin{abstract}
$\underline{\text { ABSTRACT }}$
We estimate the effect of illicit drug use during pregnancy on low birth weight. We use data from a national longitudinal study of urban parents that includes post-partum interviews with mothers, hospital medical record data on the mother and newborn, extensive demographic information on both parents, and information about the city where the mother resides. We address the potential endogeneity of prenatal drug use and present estimates using alternative measures of prenatal illicit drug use. Depending on how drug use is measured, we find deleterious effects of illicit drug use on low birth weight that range from 3 to 5 percentage points.

Kelly Noonan

Department of Economics

Rider University

2083 Lawrence Road, Room SWG 30

Lawrenceville, NJ 08648

and NBER

knoonan@rider.edu

Nancy E. Reichman

Robert Wood Johnson Medical School

University of Medicine and Dentistry of New Jersey

97 Paterson St., Room 435

New Brunswick, NJ 08903

\author{
Hope Corman \\ Department of Economics \\ Rider University \\ Lawrenceville, NJ 08648-3099 \\ and NBER \\ corman@rider.edu
}

Dhaval Dave

National Bureau of Economic Research 365 Fifth Avenue, Suite 531

New York, NY 10016-4309

and Bentley College

ddave@bentley.edu
\end{abstract}

reichmne@umdnj.edu 


\section{Introduction}

Pregnant women can invest in the health of their unborn children through the use of prenatal inputs such as nutrition and prenatal care, and by avoiding unhealthy behaviors such as smoking cigarettes and using drugs. Economists have been modeling the production of infant health for about 20 years (see, for example, Corman, Joyce and Grossman, 1987). Most of the early studies focused on the effects of positive health inputs such as prenatal care. More recently, economists have examined the unhealthy behavior of cigarette smoking during pregnancy. Although there is considerable interest among economists in studying the effects of prenatal illicit drug use on infant health, this line of inquiry has been hampered by the fact that reliable and representative data on drug use, birth outcomes, and maternal characteristics are rare, and because with available data it has been difficult to establish whether observed associations are causal.

The medical research on the topic is more extensive than the social science literature. Although the former is generally based on more refined measures of drug use than what is available in surveys, most of the studies have relied on non-random samples from individual hospital sites. As a result, the findings may not be generalizeable to a broader population. One exception is a recent multi-site analysis of over 11,000 women, which found that cocaine use during pregnancy was associated with a 150-gram decrease in birth weight, controlling for mother's age, race, marital status, education, Medicaid receipt, and a range of prenatal inputs (Bada et al. 2002). It is not clear, however, whether the estimated birth weight detriment is a direct result of prenatal cocaine use or whether it is due to an unmeasured "third" factor, such as a taste for risky behavior, that is correlated with both prenatal drug use and birth weight. 
We use an economic framework to estimate the effect of maternal illegal drug use on one important birth outcome-low birth weight, which is associated with numerous long-term health and developmental problems (see Reichman 2005). We use rich data from a national longitudinal study of urban parents that includes retrospective self-reports of drug use during pregnancy, reports of maternal drug use from hospital medical records, extensive demographic information on the mother and the father, and information about the city in which the mother resides. We use a multi-pronged approach to address the endogeneity of prenatal drug use: controlling for a large set of measures that are correlated with both drug use and birth outcomes, estimating bivariate probit models to estimate both prenatal drug use and low birth weight, and assessing the estimates to different measures of drug use and alternate model specifications. While no one strategy addresses the endogeneity issue completely, together they produce the best estimates to date of the effects of prenatal illicit drug use on low birth weight.

\section{Literature Review}

Previous research on the effects of prenatal cigarette smoking on birth weight is much more extensive and conclusive than that on the effects of illicit drug use. Although the mechanisms may be different, the empirical issues in estimating the effects of the two behaviors are similar. Below we briefly review the past research on the effects of prenatal smoking and then highlight relevant studies on illicit drugs.

\section{Prenatal cigarette smoking}

The medical literature has consistently found large and strong negative associations between prenatal cigarette smoking and birth weight, even after controlling for numerous potentially confounding factors (see Visscher et al. 2003 for an excellent review of the 
literature). All low birth weight babies are either growth retarded or preterm (they can be both), and cigarette smoking during pregnancy is strongly associated with both of these outcomes.

The economics literature on the effects of prenatal smoking, most of which relies on birth certificate data or self-reported smoking from maternal interviews, is much smaller than the medical literature but has produced results that are consistent with it. Evans \& Ringel (1999), using data on all births in Pennsylvania from 1989 to 1992, examined the impact of variation in tax rates on smoking during pregnancy and birth weight. They inferred that the direct effect of smoking on birth weight is about -370 grams. Conway \& Kennedy (2004), using data on 2,600 births to white mothers and 2,600 births to black mothers in the 1988 National Maternal and Infant Health Survey, found that poor maternal mental health is associated with an increased probability of low birth weight and that part of the association can be explained by an increased probability of smoking. Almond, Chay \& Lee (2004), as part of a much broader study of 500,000 births in Pennsylvania between 1989 and 1991, found that smoking was associated with a 3.5 percentage point increase in the probability of low birth weight.

Preliminary results from a recent study by Swaminathan \& Sen (2005), based on 11,000 births from the 1988 National Maternal and Infant Health Survey, indicate that smoking decreases birth weight by 200-250 grams. The authors estimated Two Stage Least Squares (2SLS) models, using the mother's future smoking as an identifier for prenatal smoking. Their comparison of Ordinary Least Squares (OLS) and 2SLS estimates suggests that, in their specifications, unobserved determinants of smoking are positively related to birth weight. However, because they used only one identifier, they could not implement tests to determine whether the OLS or 2SLS estimates were more appropriate.

Finally, a recent study by Lien and Evans (2005) used U.S. birth certificate data to 
estimate the effect of smoking during pregnancy on birth weight and low birth weight, using TSLS models in which prenatal smoking was estimated as a function of tax hikes on cigarettes and other covariates. They found that prenatal smoking reduces birth weight by 182 grams and increases the probability of low birth weight by approximately 7 percentage points. These estimates were similar in magnitude to those from single-equation models.

\section{Prenatal illicit drug use}

The medical literature on the effects of prenatal drug use is less conclusive than that for smoking. The studies generally use measures of drug use that are more precise than those used in economic studies (the latter generally use birth certificates). Most of the medical studies are analyses of single sites. For example, Sprauve et al. (1997) studied 483 crack cocaine users and 3158 non-users in one urban hospital. Controlling for individual-level characteristics, including prenatal care, alcohol, and tobacco use, they found that crack cocaine use (determined from urine tests) was positively associated with low birth weight (approximately a 9 percentage point increase). Little et al. (1999) found a positive association between prenatal cocaine use (determined by blood samples) and low birth weight (approximately 10 percentage points) among all mothers giving birth in one hospital in Dallas, TX over a three-week period. The sample consisted of 101 mothers who used cocaine but no other drug and 469 who used no drugs. The authors did not control for any covariates.

Two major studies in the medical literature examined data from multiple sites. Shiono et al. (1995) studied 7500 women in seven clinical centers. Controlling for numerous individuallevel characteristics including prenatal cigarette smoking, they found no significant associations between either prenatal cocaine or marijuana use (obtained from self-reports or blood tests) with birth weight, but large and significant negative associations between prenatal cigarette smoking 
and birth weight. Bada et al. (2002) used data on newborns in four large centers, measuring drug use with both maternal reports and meconium samples. They compared 1,072 cocaine-exposed infants to 7,565 cocaine-negative infants (they excluded another 3,174 cases for which cocaine use could not be determined). Controlling for a rich set of covariates, they found that cocaine use was associated with a 150-gram decrease in birth weight among infants born at 32 weeks gestation or more. They also found that smoking at least a half a pack of cigarettes a day during pregnancy was associated with a decrease in birth weight of 172 grams, while opiate use was associated with a reduction in birth weight of 72 grams. Taken together, the medical studies indicate that although there is some evidence of a negative association between prenatal drug use and birth weight, the relationship is less clear-cut and less consistent than that between cigarette smoking and birth weight. This may be because cigarettes are a homogeneous good, whereas illicit drug use can involve a number of different substances.

The economics literature on the effects of illicit drug use on birth weight is in its infancy and thus far suggests that the potential negative effect of drug use on birth weight is smaller than that of cigarette smoking. None of the existing studies addressed the potential endogeneity of prenatal drug use. Most used data from New York City. Joyce et al. (1992) use pooled timeseries cross-sectional data on health districts in New York City from 1980-1989 to investigate the relationship between drug use and low birth weight. Controlling for prenatal care, marital status, smoking, and parity, they found that a one percentage point increase in the number of pregnant women using drugs was associated with increased rates (from .14 to .43 percentage points) of low birth weight among blacks. The associations were not as strong for whites or Hispanics. Mocan \& Topyan (1995) used monthly birth certificate data from 1978-1990 for New York City. Controlling for prenatal tobacco use and prenatal care, they estimated that a 10 
percent increase in prenatal drug use (other than marijuana use) was associated with a 1 percent increase in the rate of low birth weight among black women. The corresponding association for tobacco use was slightly larger than that. The authors found no associations of tobacco or drugs with low birth weight among whites.

Particularly relevant to the present study is a study by Kaestner, Joyce \& Wehbeh (1996) of 1,300 births in one hospital in New York City in 1991-1992. The authors compared the associations of self-reported drug use and "actual" drug use (from urine screens) with birth weight, controlling for tobacco use, prenatal care, mother's age, parity, race, and multiple birth. They found that actual drug use was associated with a 6 percent decrease in the likelihood of low birth weight, whereas self-reported drug use was associated with an 8 percent decrease. This result indicates that self-reported measures of prenatal drug use lead to upward biased estimates of the effects of prenatal drug use on birth weight, and that results based on survey reports of prenatal drug use should be interpreted with caution.

In another study using a measure of "actual use," Norton et al. (1996) examined the associations of prenatal drug and alcohol use with the cost of neonatal care using data on all live births in 54 Maryland hospitals in 1991. They considered birth weight as an intermediate outcome. Their measures of drug and alcohol use were based on whether the newborn had a drug or alcohol-related disorder. They controlled for race, baby's sex, and payment source, but for no maternal characteristics (including smoking). They found that the newborn hospital costs of drug-addicted infants were about twice as high as those of non-addicted infants and that about half of the increased costs were due to low birth weight, short gestational age, or other conditions at birth. 
In the present study, we contribute to the small economics literature on the effects of prenatal drug use on birth weight in several ways: (1) We use exceptionally detailed data on both maternal and paternal characteristics; (2) we use a sample of births from a national birth cohort study of urban America; (3) we use information on substance use from both medical records and self-reports; and (4) we use statistical techniques to address the potential endogeneity of prenatal drug use and address the robustness of the results to a number of different model specifications.

\section{Data}

We use data from a recent national birth cohort survey that has been linked to medical records of mother respondents and their babies. The Fragile Families and Child Wellbeing (FFCWB) survey follows a cohort of parents and their newborn children in 20 U.S. cities (in 15 states). The survey data are rich in sociodemographic characteristics of both mothers and fathers.

The FFCWB study randomly sampled births in 75 hospitals between 1998 and 2000. By design, approximately three quarters of the mothers interviewed were unmarried. Face-to-face interviews were conducted with 4898 mothers while they were still in the hospital after giving birth. ${ }^{1}$ Mothers were re-interviewed over the telephone approximately one year later. Eighty six percent of mothers eligible for the study completed baseline interviews. Of those mothers, 90 percent completed one-year follow-up interviews. The data, when weighted, are representative of births in US cities with over 200,000 people. Additional data were collected from the hospital medical records (from the birth) for a sub-sample of 2399 non-multiple births in 14 cities (in 10 states). The medical record data contain information on prenatal drug use from laboratory tests of

\footnotetext{
${ }^{1}$ Additional background on the research design of the Fragile Families and Child Wellbeing Study is available in Reichman et al. (2001).
} 
the mother or baby and in notes by physicians or social workers (more detail is given below, under "Measures").

We use data on the 1,988 births that have medical records data as well as complete data on all analysis variables from the baseline and one-year follow-up surveys. Our sample is not representative of the population of births in the United States because: (1) births were sampled exclusively in large cities, (2) we use only a subset of the FFCWB sample for which medical record data have been collected, and (3) non-marital births are over-represented and we do not use weighted data. Nevertheless, our sample represents an important group to study from a public policy standpoint in that it is likely to include chronic or heavy users.

\section{Measures}

Low birth weight

We focus on low birth weight $(<2500$ grams) as a dichotomous outcome rather than birth weight in grams because the former is the more clinically relevant measure. However, we conduct auxiliary analyses of birth weight in grams and report those results. The rate of low birth weight in our sample, at 9.4 percent, is somewhat higher than the corresponding figure for all births in U.S. cities with over 100,000 people-8.4 percent (National Center for Health Statistics 1999), likely reflecting the over-sampling of non-marital births in the FFCWB study.

\section{Prenatal illicit drug use}

Risky behaviors are notoriously under-reported. New mothers may be particularly likely to under-report prenatal drug use because of the illegal nature and stigma associated with that behavior and fear of child protective services involvement. Kaestner et al. (1996) modeled the measurement error in self-reported drug use by combining data on self-reports with "actual use" 
based on urine tests. They found that only 17 percent of women who tested positive for illicit drug use at the time their children were born reported that they had used drugs.

Arendt et al. (1999) compared the sensitivity of different sources of data on prenatal cocaine use (medical records, urine screens, meconium analyses, and postpartum interviews) for 323 births. They assumed no false positives from any source. Surprisingly, the clinical measures (urine and meconium screens, together) revealed fewer cases of cocaine use than medical records in conjunction with post-partum interviews. They concluded that a combination of medical records analysis and post-partum interview is the best way to ascertain prenatal cocaine use.

Although the Fragile Families interview was far less detailed on illicit drug use than that used by Arendt et al., we adopt the strategy of combining responses to a post-partum survey with a review of the mothers' and babies' medical records. During the mother's interview in the hospital after giving birth, she was asked whether she had used any illicit drugs during her pregnancy, but not about the specific types of drugs she may have used. ${ }^{2}$ One hundred six mothers (5.3\%) in our sample reported that they had used drugs (at all) during pregnancy.

The medical records contain information about the mother's drug use during pregnancy from laboratory tests of the mother or baby and in notes by physicians, nurses, or social workers. Forty five percent of the 1,988 mothers in our sample had results from urine toxin screens in their charts; of these, 111 (12.4\%) tested positive for cocaine, heroin, marijuana, other drugs (including amphetamines, methadone and barbiturates/benzioazepines) or unspecified drugs, or a combination of drugs. Another 88 cases of prenatal drug use were picked up from notes in various places in the mothers' and babies' charts. Overall, $199(10 \%)$ of the mothers in our

\footnotetext{
${ }^{2}$ The exact question asked was: "During your pregnancy, about how often did you use drugs such as marijuana, crack cocaine, or heroin-- nearly every day, several times a week, several times a month, less than once a month, or never." When coding prenatal drug use based on the interview responses, those answering anything but "never" were considered prenatal drug users.
} 
sample had some indication of prenatal drug use recorded in their own or their baby's chart; of those, 16.1 percent used cocaine, 3.5 percent used heroin, 46.7 percent used marijuana, 3.5 percent used other or unspecified drugs, and 30.2 percent used a combination of drugs.

We constructed three measures of prenatal drug use: whether the mother indicated in the postpartum interview that she had used illicit drugs at all during the pregnancy (5.3\%), whether there was any indication of prenatal drug use from the interview or medical records $(10.9 \%)$, and whether there was any indication of prenatal drug use other than marijuana from the medical records $(6.2 \%)$. We refer to the last measure as "hard drug" use. ${ }^{3}$ These percentages are in the range presented in a review of sixteen studies by Howell et al. (1999). They are higher than the rates found in a recent survey that asked individuals whether they were pregnant, and if they were, whether they had used any illicit drugs in the past month (about 3.3\%) and whether they had used any hard drugs in the past month (1.1\%) (Substance Abuse and Mental Health Services Administration [SAMHSA], 2000). ${ }^{4}$

\section{Prenatal cigarette smoking}

Three hundred seventy four (19\%) of the mothers in our sample reported smoking cigarettes during pregnancy in their baseline interviews, compared to 452 (23\%) who smoked according to either their interview self-reports or their medical records. These figures are

\footnotetext{
${ }^{3}$ The measure of hard drugs is based solely on the medical records, since we cannot distinguish marijuana from other drugs using the survey reports. Thus, this measure may not capture all of the self-reporters who used hard drugs.

${ }^{4}$ The SAMHSA data are from the National Household Survey on Drug Abuse for 2000 and, when weighted, are representative of the U.S. population age 12 and over. The specific computation was for pregnant women age 15 to 44 within the overall sample. http://www.oas.samhsa.gov/nhsda/2kdetailedtabs/Vol_1_Part_4/sect6v1.htm\#6.23b.
} 
comparable to national estimates, which indicate that about 19 percent of pregnant women report smoking in the past month. ${ }^{5}$

\section{Other analysis variables}

One of the advantages of the FFCWB data is that they include a rich set of characteristics on the mother, father, and the parents' relationship status that may be associated with both prenatal drug use and low birth weight. Table 1 shows the means of the analysis variables other than low birth weight, prenatal drug use, and prenatal smoking. We include a basic set of covariates that are typically used in analyses of prenatal substance use and are available in birth certificate data - maternal age (in years), education (which we code as high school graduate, some college but not a graduate, or college graduate - compared to less than high school), race/ethnicity (non-Hispanic black, Hispanic, or other non-white non-Hispanic — compared to non Hispanic white), nativity (whether the mother was foreign-born), and parity (whether it was the mother's first birth). We also include insurance information (whether the birth was covered by Medicaid or other government program — henceforth referred to as "Medicaid"), whether the mother lived with both of her parents at age 15 , whether she reported that she attends religious services regularly (several times per month), whether she was married at the time of conception, ${ }^{6}$ whether she knew the father at least a year prior to conception, ${ }^{7}$ the number of previous pregnancies that the mother had (whether they resulted in live births or not), the father's age (expressed as the number of years the father's age exceeded the mother's age), whether the father

\footnotetext{
5 Source: SAMHSA, National Household Survey on Drug Abuse, 2000. http://www.oas.samhsa.gov/nhsda/2kdetailedtabs/Vol_1_Part_4/sect6v1.htm\#6.26b.

${ }^{6}$ This variable is based on marriage dates, birth dates, and the baby's gestational age. It reflects whether the mother was married to the baby's father rather than whether she was married at all, and is used instead of marital status at birth in order to purge "shotgun marriages" from the married group.

7 This variable is based on the baby's birth date and gestational age, as well as the mother's report of how long she knew the father.
} 
was a different race-ethnicity than the mother, and the father's education (using the same educational categories as for the mother). ${ }^{8}$ We also control for whether the infant was male.

In certain analyses, we included whether the mother consumed any alcohol during pregnancy, ascertained from either the interview or the medical records. Two hundred one women (10.1\%) reported that they had consumed alcohol (at all) during the pregnancy, and another 83 cases of prenatal alcohol use were picked up from the medical records. In some analyses, we use a measure of mother's future drug use (from the mothers' reports at the oneyear follow-up interview of whether they had used marijuana, cocaine, crack, speed, LSD, heroin, or any other kind of hard drug in the past month) and future smoking (from the mothers' reports at one year whether they had smoked cigarettes at all in the past month). Finally, we used the three-year average price per gram of pure cocaine (in tens of dollars) in the city in which the mother gave birth (for the year of the birth and the two previous years). These data are from The System to Retrieve Information from Drug Evidence (STRIDE), maintained by the Drug Enforcement Agency (see Corman et al. 2004 for more information about the STRIDE data).

\section{Illicit drug use, cigarette smoking, and low birth weight}

Kaestner et al. (1996) found that self-reported drug use had a stronger association with birth weight than did any evidence of drug use. The authors inferred that users who self-report are either heavier users or use more addictive drugs than are users who do not self-report. Approximately half of the mothers in our sample who used drugs (according to self-reports or medical records) reported that they had done so, whereas over 80 percent of cigarette smokers (according to self-reports or medical records) reported having engaged in that behavior during

\footnotetext{
${ }^{8}$ Because of cell sizes, we collapsed fathers' education to high school or more versus less than a high school diploma in the probit model with self-reported drug use.
} 
pregnancy (see Table 2). ${ }^{9}$ We find that the hard drug users were more likely to self-report than were all drug users (56\% versus $49 \%$ ). Even so, a sizeable fraction of known hard drug users reported that they had not used drugs during pregnancy.

Substance users are far more likely than non-users to have low birth weight babies (see Table 2). The percentage of drug users having low birth weight babies ranged from about 20 percent for all drug users to 25 percent for self-reported drug users. The rate of low birth weight among cigarette smokers was 19 to 20 percent. From Table 2 it appears that: (1) illicit drug use is an even more substantial risk factor for low birth weight than smoking, (2) both smoking and drug use more than double the risk for low birth weight, and (3) drug users who self-report are at greater risk for having low birth weight babies than users who do not self-report.

Since both illicit drug use and smoking appear to be important risk factors for low birth weight, it is important to consider the co-occurrence of the two behaviors. Among drug users, the rate of smoking is very high (see Table 3$)$. Almost two thirds $(62 \%=66 / 106)$ of self-reported drug users also self-reported smoking. About 69 percent (86/124) of hard drug users also smoked (according to self-reports or medical records). Less than one fifth $(18 \%=66 / 374)$ of selfreported smokers also self-reported drug use, and about one third $(31 \%=141 / 452)$ of all smokers (according to self-reports or medical records) used any illicit drugs (again, according to self-reports or medical records). Due to the considerable co-occurrence of drug use and smoking, associations of each of these behaviors with birth weight, when not controlling for the other, should be interpreted with caution.

\footnotetext{
${ }^{9}$ Kaestner et al. (1996) found that about 27 percent of drug users self-reported.
} 


\section{Estimation Strategy}

We estimate the effects of prenatal illicit drug use on low birth weight among a sample of urban, mostly unmarried mothers. Following the basic structure of Corman, Joyce and Grossman (1987), we can model a birth weight production function as follows:

(1) Low birth weight $=f\left(\right.$ input $_{1}$, input ${ }_{2}, \ldots$ input $\left._{n}\right)$, with the following input demand functions:

(2) Input $_{1}=g_{1}$ (price of input 1, prices of substitute and complementary inputs, income, tastes)

Input $_{2}=g_{2}$ ( price of input 2, prices of substitute and complementary inputs, income, tastes)

Input $_{n}=g_{n}$ ( price of input $n$, prices of substitute and complementary inputs, income, tastes)

One approach is to estimate Equation 1 and treat all inputs, such as smoking, drug use, and prenatal care as endogenous. ${ }^{10}$ Such a system of equations is difficult to implement empirically. An alternative approach, implemented by Corman, Joyce and Grossman (1987), is to treat only a subset of inputs as endogenous and substitute the right-hand variables of the input demand equations for the other potentially endogenous inputs. This is referred to as a "quasistructural production function." This approach is particularly useful in the current case, as we are interested primarily in the effect of one input--illicit drug use. Therefore, we substitute factors related to the demand for other inputs into Equation 1, and estimate the following quasistructural production function:

(3) Low birth weight $=$ h(illicit drug use, smoking, gender of child, parents' characteristics) 
Maternal and paternal characteristics serve as proxies for income and tastes. We include smoking in the production function because that behavior is negatively associated with birth weight and it is highly correlated with drug use. As discussed earlier, excluding smoking would likely result in overestimation of the effect of illicit drug use on birth weight.

Estimation of Equation 3 poses several challenges for researchers. First, most data sets contain information on prenatal drug use that comes from mothers' own reports. If mothers who self-report are a non-random sample of prenatal drug using mothers, then estimates of the effects of drug use on birth weight would be biased. Indeed, Kaestner et al. (1996) found that selfreported drug use overestimates the negative effect of actual drug use on birth weight. For this reason, we include measures of prenatal drug use from both self-reports and from medical records in our analyses.

Another issue is that different types of illicit drugs could have differential impacts on birth weight. For example, most research does not find a deleterious effect of marijuana on birth weight (see, for example, Bada et al. 2002). For these reasons, we examine whether the estimated effects of prenatal drug use on low birth weight vary across three different measures of prenatal drug use: self-reported, any indication, and hard drug use (as defined earlier).

Finally, and most importantly, if there are unobserved factors that are associated with both illicit drug use and birth weight, estimates of the effect of drug use on low birth weight will be biased. As prenatal drug use is a choice made by the mother, it is possible that, even with rich data, there are unmeasured characteristics of mothers that are associated with both prenatal drug use and low birth weight. For example, if mothers have tastes for risky behavior that are unmeasured, then we might expect a positive correlation between the unobserved determinants of drug use and low birth weight. In this case, the coefficient for drug use in Equation 3 would

\footnotetext{
${ }^{10}$ For example, see Rosenzweig and Schultz (1983).
} 
overstate the deleterious effects of drug use on birth weight. It is also possible that mothers with poor health endowments are more likely to refrain from using illicit substances during pregnancy in order to protect the baby. In this case, the correlation between the unobserved determinants of drug use and low birth weight would be negative and Equation 3 would understate the true deleterious effect.

Since randomized experiments would not be feasible, the effects of prenatal drug use on birth outcomes must be ascertained from retrospective data analysis, which is limited in its ability to establish causal relationships. Studies relying on multivariate regression analysis, exploiting geographic variations in policies or services, or comparing siblings all have limitations (see Moffitt 2005 for an excellent discussion of the issues). Because we have very rich and well-measured data, we estimate Equation 3 directly. We also estimate a two-equation system that models both prenatal drug use and low birth weight, recognizing that such techniques are also limited, perhaps even more so than the models they are intended to improve. We assess robustness of the results to different measures and model specifications. Although no retrospective analysis provides an airtight and generalizable case for causal relationships, our analyses produce the best estimates to date of the effects of prenatal illicit drug use on low birth weight — a topic on which there has been very little social science research.

We use a probit model to estimate low birth weight in a single equation form (Equation 3). As discussed above, we also estimate a bivariate probit model, in which there is one equation for birth weight (Equation 3) and another that is an input demand function for illicit drug use, as follows:

(4) Illicit Drug Use = j(maternal and paternal characteristics, gender of the child, smoking, identifiers) 
For the identifiers in Equation 4 to be valid, they must be conceptually valid and they need to be significant predictors of drug use (Equation 4), but not of low birth weight when controlling for drug use and the other covariates (Equation 3). We use three identifiers that fit these criteria: city-level cocaine prices, whether the mother consumed alcohol during the pregnancy, and whether the mother reported in the one year follow-up interview that she had used drugs in the past month. In previous research (Corman et al. 2005), we found that prenatal drug use is fairly responsive to variations in price. Alcohol and illicit drugs are complementary goods, and although prenatal alcohol use is associated with fetal alcohol syndrome and certain other child disabilities, few to no studies have found associations between prenatal alcohol consumption and birth weight (see Tough et al. 2001). Among the mothers who did not use drugs in our sample, 8 percent of those who consumed alcohol and 9 percent of those who did not consume alcohol had low birth weight babies, and the difference is not statistically significant. Future drug use, which has been used in empirical models of rational addiction (see, for example, Chaloupka 1991), should not affect current birth outcomes conditional on prenatal drug use. We estimate bivariate probit models with all three of these identifiers, as well as with pairs of them.

\section{Results}

We present single equation probit estimates of the effects of prenatal illicit drug use and the other covariates on low birth weight, as well as bivariate probit estimates for both low birth weight and prenatal drug use. In all cases, we present coefficients, marginal effects, and robust standard errors that are corrected for clustering at the city level. 


\section{Single-equation estimates}

Table 4 presents results for the probit models. As discussed earlier, we use three different measures of drug use: self-reports, any indication of drug use (from self-reports or medical records), and hard drug use (as defined earlier). In all models, drug use is found to increase the probability of low birth weight, controlling for cigarette smoking and the other covariates. Probit models yield estimates ranging from 3 to 5 percentage points. ${ }^{11}$ The associations of drug use with low birth weight are statistically significant when using self-reports or hard drugs. The associations are smaller and are not statistically significant when using the broadest measureany drug use. The multivariate associations between drug use and low birth weight are much smaller than the unadjusted associations (from Table 2).

The associations of cigarette smoking with low birth weight are slightly larger than those of drug use with low birth weight and they are uniformly significant at the 1 percent level. In contrast, the unadjusted associations (from Table 2) of prenatal smoking with low birth weight appeared to be stronger for than those of prenatal drug use and low birth weight. The multivariate result is more consistent with the past research discussed earlier.

Other than substance use, the variable most associated with low birth weight and significant is whether the birth was financed by Medicaid - a proxy for poverty, and possibly for reduced availability of high-quality prenatal care. Another variable associated with low birth weight in the multivariate context is our indicator for the father being of a different race-ethnicity than the mother. Surprisingly few of the other variables are significant predictors of low birth weight in our models. These results are similar across measures of illicit drug use.

\footnotetext{
${ }^{11}$ For the probit models, marginal effects are calculated at the mean values of the independent variables.
} 


\section{Two-equation estimates}

As part of our multi-pronged estimation strategy, we estimate bivariate probit models. The results are presented in Appendix Table 1; the low birth weight estimates are in 1(a) and the prenatal drug use estimates are in 1(b). The estimates of the effects of prenatal drug use on low birth weight are very similar to those from the single-equation models, although the standard errors are higher in the bivariate probit models so the coefficients of drug use are not statistically significant. Each of the three identifiers - city-level cocaine price, alcohol use during pregnancy, and future self-reported drug use - is significantly related to prenatal drug use. Both alcohol use and future drug use are significant at the 1 percent level and cocaine price is significant at the 10 percent level or better. As expected, prenatal alcohol use and future drug use are positively related to, and cocaine prices are negatively related to, prenatal drug use. The three identifiers are jointly significant at the 1 percent level in all models (test statistics and p-values are shown in Appendix Table 1b).

In all bivariate probit models, each is the identifiers is insignificant in predicting low birth weight and therefore excludable from the low birth weight equation (test statistics and pvalues shown in Appendix Table 1b). In all cases, the correlations between the error terms of the drug use and the low birth weight equations are not statistically different from zero. Therefore, we are unable to reject the null hypothesis of zero correlation between the error terms in the two equations (test statistics and p values in Appendix Table 1b). Based on these model specifications, we should rely on the single-equation models to get unbiased estimates of the effects of prenatal drug use on low birth weight. 


\section{Auxiliary analyses}

Here we report results from auxiliary analyses that address: how the effects of drug use on low birth weight translate to average effects on birth weight in grams, the potential endogeneity of prenatal cigarette smoking, the sensitivity of our bivariate probit results to which of the three identifiers are used, whether the estimates are sensitive to the inclusion of prenatal care in the model, and whether the results can be generalized to the entire Fragile Families sample. $^{12}$

\section{$\underline{\text { Effects of prenatal drug use on mean birth weight }}$}

Although low birth weight is a more clinically relevant measure than birth weight in grams, estimating the latter is informative for comparison with other studies. In a separate set of analyses, we estimated single-equation models with birth weight as a continuous variable. The results are presented in Table 5. We found that prenatal drug use led to a reduction in birth weight of between 99 and 164 grams. The associations between the other covariates and birth weight were similar to those in other studies.

\section{Endogeneity of prenatal smoking}

Both our single-and two-stage estimates of drug use on low birth weight treated prenatal cigarette smoking as an exogenous variable. We test this assumption. Swaminathan and Sen (2005) recently estimated a birth weight production function that treated smoking as endogenous, but used only one identifier and therefore were unable to conduct overidentification tests. We use two identifiers to estimate two-stage models of the effects of cigarette smoking on low birth weight: alcohol use during pregnancy and self-reported smoking at the one year follow-up

\footnotetext{
${ }^{12}$ The latter four auxiliary analyses are not shown, but are available upon request.
} 
interview. ${ }^{13}$ In each of our models (bivariate probit using smoking from self reports or medical records, results not shown), we find that: the two identifiers significantly predict smoking in the expected direction, both are excludable from the low birth weight equation, and the correlations of the error terms in the smoking and the low birth weight equations are insignificant. Thus, smoking is not found to be endogenous in our models that control for a rich set of covariates and therefore unlikely biases the estimated effects of prenatal drug use.

Although the single equation model is preferred, the marginal effects of smoking on low birth weight are very similar in the single-equation models ( 8 to 9 percentage points) and the two-stage models (13 to 14 percentage points). Additionally, smoking is uniformly significant at the 1 percent level, regardless of specification. Overall, we find somewhat stronger and more robust effects of smoking than of illicit drug use on low birth weight. ${ }^{14}$ Robustness of estimates to choice of identifiers

To be sure that our two-stage results present in the Appendix do not hinge on any one of the three identifiers, we estimated (results not shown) all two-stage models with pairs of those identifiers (instead of all three). Regardless of the measure of actual drug use used, each identifier significantly predicted drug use and was excludable from the low birth weight equation. In all cases, we were unable to reject the null hypothesis of zero correlation between the error terms in the two equations.

Inclusion of prenatal care

We excluded prenatal care from the main models because of the empirical difficulties, discussed earlier, of treating multiple inputs as endogenous. We ran a full set of low birth weight

\footnotetext{
${ }^{13}$ State cigarette prices were not significant in predicting prenatal smoking and were therefore not included in the analyses.
} 
models that also included a dichotomous indicator for whether the mother obtained prenatal care during the first trimester (results not shown). The estimated effects of drug use on low birth weight were not sensitive to whether prenatal care was included.

\section{$\underline{\text { Full Sample Results }}$}

Since we limited most of the analyses to 1,988 of the 4,898 mothers in the Fragile Families study, we were concerned about sample selectivity. We ran a probit model using selfreported drug use using the full sample (results not shown). We found the effect of self-reported drug use on low birth weight in the full sample to be similar to the corresponding estimate for the smaller sample with medical records data.

Overall, the evidence suggests that illicit drug use has deleterious effects on low birth weight of between 3 and 5 percentage points. The estimates are robust across numerous different model specifications and using different measures of drug use. Consistent with Kaestner et al. (1996) and a previous finding of our own that prenatal drug users with relatively inelastic demand are more likely than those with more elastic demand to report prenatal drug use (Corman et al. 2004), we find that the effects are larger and more significant for mothers who self-report and those who use hard drugs than for those with any indication of illicit drug use during pregnancy. We also find that the effect of cigarette smoking on low birth weight -8 to 9 percentage points — is larger and even more robust than that of illicit drug use.

\section{Conclusion}

\footnotetext{
${ }^{14}$ The more robust results for cigarette smoking than illicit drug use likely reflect that cigarettes are a homogeneous good, whereas illicit drug use can involve a number of different substances. Our three different measures of drug use
} 
Our result that prenatal illicit drug use increases the likelihood of low birth weight by 3 to 5 percentage points confirms the widespread belief that prenatal drug use is harmful to the fetus. It also underscores the importance of preventing drug use among women of childbearing age, collecting reliable data on illicit drug use as part of regular medical care (preferably prior to pregnancy), and providing substance abuse treatment to users of illicit drugs. In previous work, we found that demand for illicit drugs among pregnant women is fairly elastic (Corman et al. 2004), which with our results from this study suggests that drug enforcement is a potentially promising tool for improving birth outcomes. This study also provided evidence that the wellestablished association between prenatal cigarette smoking and low birth weight appears to be causal, underscoring the importance of reducing cigarette smoking among women of childbearing age.

are intended to give ranges of estimates that take into consideration that drugs are a heterogeneous good. 


\section{References}

Almond, Douglas, Kenneth Y. Chay and David S. Lee (2004) " The Costs of Low Birth Weight," NBER Working Paper No. w10552.

Arendt, R. E., L. T. Singer, S. Minnes and A. Salvator. (1999). "Accuracy in Detecting Prenatal Drug Exposure." Journal of Drug Issues 29(2): 203-214.

Bada, H.S., A. Das, C.R. Bauer, S. Shankaran, B. Lester, L. L. Wright, J. Verter, V.L. Smeriglio, L. P. Finnegan and P. L. Maza (2002). "Gestational Cocaine Exposure and Intrauterine Growth: Maternal Lifestyle Study" Obstetrics and Gynecology 100 (5/1): 916-924.

Chaloupka (1991). "Rational Addictive Behavior and Cigarette Smoking." Journal of Political Economy 99(4): 722-42.

Conway, K.S. and L.D. Kennedy (2004) "Maternal Depression and the Production of Infant Health.” Southern Economic Journal 71(2): 260-286.

Corman, H., T. Joyce and M. Grossman (1987). "Birth Outcome Production Function in the United States." The Journal of Human Resources 22(3): 339-360.

Corman, H., K. Noonan, N.E. Reichman and D. Dave (2005). "Demand for Illicit Drugs Among Pregnant Women." Advances in Health Economics and Health Services Research 16: 41-60.

Evans, W. N. and J. S. Ringel (1999). "Can Higher Cigarette Taxes Improve Birth Outcomes?" Journal of Public Economics 72: 135-154

Howell, E. M., N. Heiser and M. Harrington. (1999). "A Review of Recent Findings on Substance Abuse Treatment for Pregnant Women." Journal of Substance Abuse Treatment 16(3): 195-219.

Joyce, T., A. D. Racine and N. Mocan (1992) "The Consequences and Costs of Maternal Substance Abuse in New York City: A Pooled Time-Series, Cross-section Analysis." Journal of Health Economics 11(3): 297-314.

Kaestner, Robert, Theodore Joyce and Hassan Wehbeh (1996). "The Effect of Maternal Drug Use on Birth Weight: Measurement Error in Binary Variables." Economic Inquiry 34:326-352.

Lien, Diana S. and William N. Evans. (2005) "Estimating the Impact of Large Cigarette Tax Hikes: The Case of Maternal Smoking and Infant Birth Weight." Journal of Human Resources 40(2): 373-392. 
Little, B. B. L.M. Snell, K.J. Trimmer, S. M. Ramin, F. Ghali, C. A. Blakely and A. Garret (1999). "Peripartum Cocaine Use and Adverse Pregnancy Outcome." American Journal of Human Biology 11:598-602.

Moffitt, R. (2005). "The Analysis of Causal Relationships in Population Research.” Demography 42 (1): 91-108.

Mocan, N. and K. Topyan (1995). "Illicit Drug Use and Health: Analysis and Projections of New York City Birth Outcomes Using a Kalman Filter Model.” Southern Economic Journal 62(1): 164-82.

National Center for Health Statistics, Vital Statistics of the United States, 1999. http://www.cdc.gov/nchs/datawh/statab/unpubd/natality/natab99.htm.

Norton, E.C., G.A. Zarkin, B. Calingaert and C. J. Bradley (1996). "The Effect of Maternal Substance Use on the Cost of Neonatal Care.” Inquiry 33: 247-257

Reichman, N. (2005). Low Birth Weight and School Readiness. The Future of Children 15(1): $91-116$.

Reichman, N. E., J. O. Teitler, I. Garfinkel and S. S. McLanahan (2001). "Fragile Families: Sample and Design." Children and Youth Services Review 23(4/5): 303-326.

Shiono, P. H., M. S. Klebanoff, R. P. Nugent, M. F. Cotch, D. G. Wilkins, D. E. Rollins, J. C. Carey and R. E. Behrman (1995). "The Impact of Cocaine and Marijuana Use on Low Birth Weight and Preterm Birth: A Multicenter Study." American Journal of Obstetrics and Gynecology 172: 19-27

SAMHSA, National Household Survey on Drug Abuse for 2000. http://www.oas.samhsa.gov

Sprauve, M. E., M. Lindsay, S. Herbert and W. Graves (1997). "Adverse Perinatal Outcome in Parturients Who Use Crack Cocaine." Obstetrics and Gynecology 89(5/1): 674-678

Swaminathan S. and B. Sen (2005). "Effects of Maternal Substance Abuse During Pregnancy on Child Birth weight: The Bias Due to Selective Fetal Mortality" Presented at the American Economics Association meeting, Jan. 2005, Philadephia, PA.

Tough, S. C., L/W. Svenson, D.W. Johnston and D. Schopflocher (2001). "Characteristics of Preterm Delivery and Low Birthweight Among 113,994 Infants in Alberta: 1994-1996." Canadian Journal of Public Health 92(4): 276-280.

Visscher, W. A., M. Feder, A. M. Burns, T. M. Brady and R. M. Bray (2003). "The Impact of Smoking and Other Substance Use on Urban Women on the Birthweight of Their Infants." Substance Use and Misuse 38(8): 1063-2003. 
Table 1: Means $(\mathrm{N}=1,988)$

\section{Mother Characteristics}

Less Than High School*

High School Graduate $\quad .31$

Some College $\quad .24$

College Graduate $\quad .09$

Medicaid Birth $\quad .67$

Non-Hispanic White* $\quad .82$

Hispanic $\quad .31$

Non-Hispanic Black $\quad .45$

Other Non-White Non-Hispanic $\quad .04$

Immigrant $\quad .17$

Lived With Both Parents At Age 15

First Birth $\quad .37$

Number of Previous Pregnancies $\quad .76$

Attends Religious Services $\quad .38$

Several Times/Month

\section{Child Characteristic}

Male

\section{Father Characteristics}

Less Than High School*

High School Graduate $\quad .35$

Some College $\quad .21$

College Graduate $\quad .08$

Different Race-Ethnicity Than Mother $\quad .16$

Age Difference in Years 2.63

(father minus mother)

\section{Parents' Relationship}

Knew Each Other 12 Months $\quad .85$

Married at Conception $\quad .22$

Other Measures

Mother Used Drugs (1Year) $\quad .02$

Price Per Gram of Cocaine in City (tens of $\quad 9.16$

dollars) (2.02)

Prenatal Alcohol Use $\quad .14$

Mother Smoked Cigarettes (1Year) $\quad .26$

*Omitted Category 
Table 2. Prenatal Drug Use, Prenatal Smoking, and Low Birth Weight

\begin{tabular}{lcccc}
\hline & $\begin{array}{c}\text { Number of } \\
\text { observations }\end{array}$ & \% of sample & $\begin{array}{c}\text { \% Users Who } \\
\text { Self-Reported }\end{array}$ & $\begin{array}{c}\text { \% Low } \\
\text { Birth weight }\end{array}$ \\
\hline Full Sample & 1988 & 100 & & 9.41 \\
$\begin{array}{l}\text { Self-Reported Drug Use } \\
\begin{array}{l}\text { Any Drug Use } \\
\text { from self-report or medical records) }\end{array}\end{array}$ & 106 & 5.3 & 100 & 24.53 \\
$\begin{array}{l}\text { Hard Drug Use } \\
\text { (from medical records) }\end{array}$ & 124 & 10.9 & 48.85 & 19.82 \\
$\begin{array}{l}\text { Self-Reported Smoking } \\
\text { Any Smoking } \\
\text { from self-report or medical records) }\end{array}$ & 374 & 6.2 & 56.45 & 23.39 \\
\hline
\end{tabular}


Table 3. Numbers of prenatal drug users and smokers in sample, according to source of information

\begin{tabular}{lcccc}
\hline & $\begin{array}{c}\text { Used Drugs } \\
\text { (self-report) }\end{array}$ & $\begin{array}{c}\text { Used Drugs } \\
\text { (self-report } \\
\text { or medical record) }\end{array}$ & $\begin{array}{c}\text { Used Hard Drugs } \\
\text { (medical record) }\end{array}$ & Total* \\
\hline $\begin{array}{l}\text { Smoked } \\
\text { (self-report) }\end{array}$ & 66 & 116 & 74 & 374 \\
$\begin{array}{l}\text { Smoked } \\
\text { (self-report or medical record) }\end{array}$ & 75 & 141 & 86 & 452 \\
& 106 & 217 & 124 \\
Total** & & & \\
\hline
\end{tabular}

*Figures do not represent column totals

**Figures do not represent row totals 
Table 4: Probit estimates of the effects prenatal drug use on low birth weight $(<2500$ grams $)$

\begin{tabular}{ccc} 
Self-Reported & Any Drug Use & Hard Drug Use \\
\hline Coefficient & \\
& [Marginal Effect] \\
& (Standard Error) \\
\hline
\end{tabular}

\section{Mother Characteristics}

Self-Reported Drug Use

$.31 * *$

$[.05]$

$(0.13)$

Any Drug Use

.18

[.03]

(0.14)

Hard Drug Use

$.26 * *$

[.05]

$(0.12)$

Self-Reported Smoking

$.49 * * *$

[.09]

$(0.10)$

Any Smoking During Pregnancy

$.47 * * *$

$.47 * * *$

(0.13)

[.08]

Age, in years

$-.03$

$[-.00]$

$(0.06)$

$-.02$

$-.03$

$[-.00]$

[-.00]

$(0.05)$

$(0.06)$

Age Squared

.00

[.00]

$(0.00)$

.00

.00

[.00]

$(0.00)$

[.00]

.00

[.00]

$(0.09)$

$-.00$

$(0.00)$

High School Graduate

[-.00]

.01

$(0.10)$

[.00]

$-.14 *$

[-.02]

Some College (but not graduate)

(0.08)

$-.14 *$

College Graduate

$-.03$

[-.00]

$(0.20)$

[-.02]

$-.13$

$(0.08)$

[-.02]

$(0.08)$

Medicaid Birth

$.35 * * *$

[.05]

$-.02$

$-.00$

[-.00]

[-.00]

(0.21)

$(0.22)$

(0.11)

$.35 * * *$

$.35 * * *$

[.05]

[.05]

(0.11) 


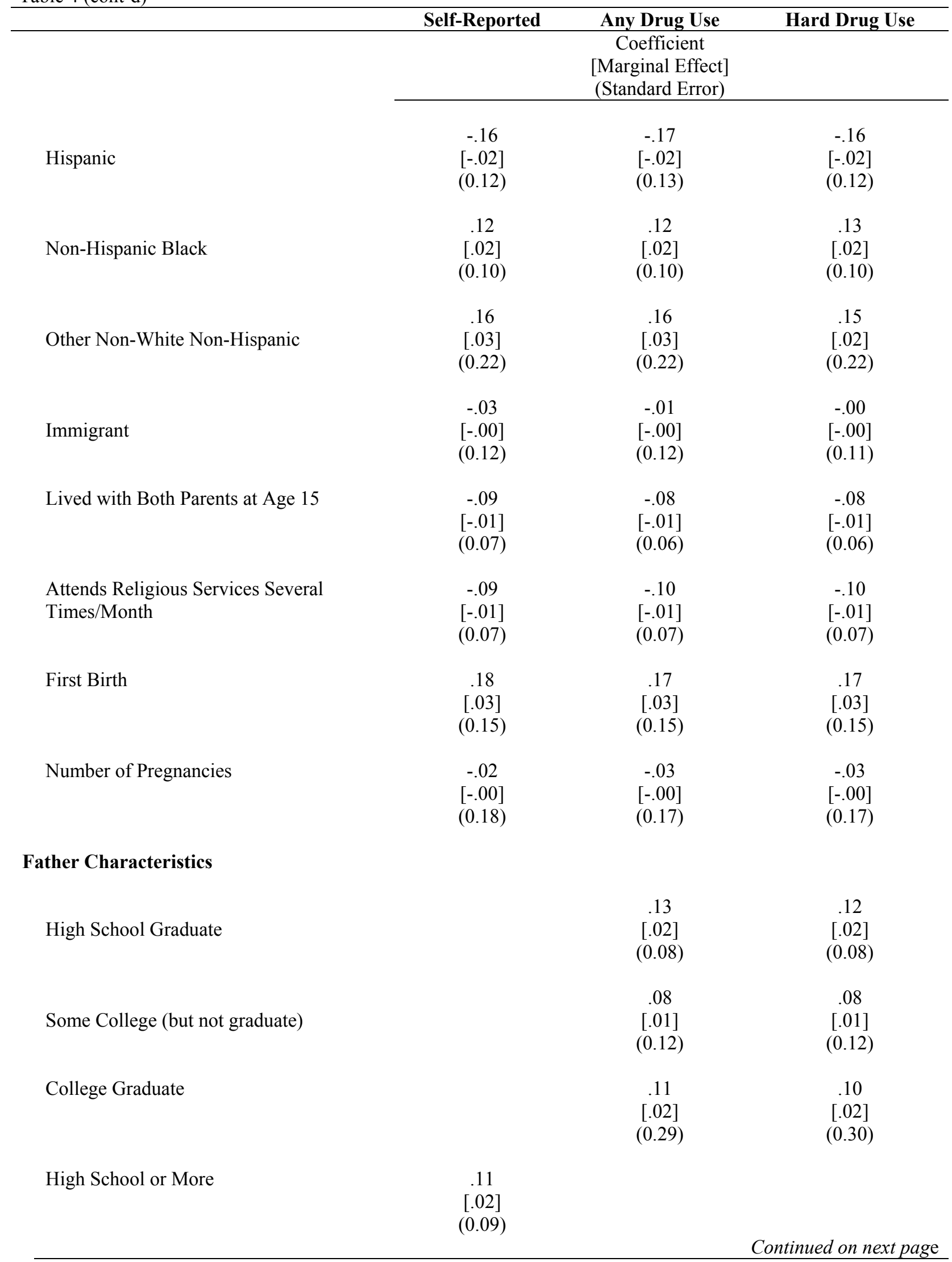


Table 4 (cont'd)

\begin{tabular}{|c|c|c|c|}
\hline \multirow[b]{3}{*}{ Different Race-Ethnicity Than Mother } & Self-Reported & Any Drug Use & Hard Drug Use \\
\hline & & $\begin{array}{c}\text { Coefficient } \\
\text { [Marginal Effect] } \\
\text { (Standard Error) }\end{array}$ & \\
\hline & $\begin{array}{l}-.28^{* *} \\
{[-.04]} \\
(0.13)\end{array}$ & $\begin{array}{l}-.27^{* *} \\
{[-.03]} \\
(0.13)\end{array}$ & $\begin{array}{l}-.26^{* *} \\
{[-.03]} \\
(0.13)\end{array}$ \\
\hline $\begin{array}{l}\text { Age Difference in Years (father minus } \\
\text { mother) }\end{array}$ & $\begin{array}{c}.01 \\
{[.00]} \\
(0.01)\end{array}$ & $\begin{array}{c}.01 \\
{[.00]} \\
(0.01)\end{array}$ & $\begin{array}{c}.01 \\
{[.00]} \\
(0.01)\end{array}$ \\
\hline \multicolumn{4}{|l|}{ Child Characteristic } \\
\hline Male & $\begin{array}{c}-.00 \\
{[-.00]} \\
(0.09)\end{array}$ & $\begin{array}{l}-.02 \\
{[-.00]} \\
(0.09)\end{array}$ & $\begin{array}{c}-.02 \\
{[-.00]} \\
(0.09)\end{array}$ \\
\hline \multicolumn{4}{|l|}{ Parents' Relationship } \\
\hline $\begin{array}{l}\text { Mother Knew Father } 12 \text { Months Prior to } \\
\text { Conception }\end{array}$ & $\begin{array}{c}-.10 \\
{[-.01]} \\
(0.11)\end{array}$ & $\begin{array}{c}-.09 \\
{[-.01]} \\
(0.10)\end{array}$ & $\begin{array}{c}-.09 \\
{[-.01]} \\
(0.10)\end{array}$ \\
\hline Married at Time of Conception & $\begin{array}{c}-.15 \\
{[-.02]} \\
(0.12)\end{array}$ & $\begin{array}{c}-.14 \\
{[-.02]} \\
(0.12)\end{array}$ & $\begin{array}{c}-.14 \\
{[-.02]} \\
(0.12)\end{array}$ \\
\hline Pseudo $\mathrm{R}^{2}$ & .08 & .08 & .08 \\
\hline $\mathrm{N}$ & 1988 & 1988 & 1988 \\
\hline
\end{tabular}


Table 5: OLS estimates of the effects of prenatal drug use on birth weight in grams

\begin{tabular}{ccc} 
Self-Reported & Any Drug Use & Hard Drug Use \\
\hline & Coefficient & \\
(Standard Error) & \\
\hline
\end{tabular}

\section{Mother Characteristics}

Self-Reported Drug Use

$-158.44^{*}$

$(82.35)$

Self-Reported Smoking

$-247.72 * * *$

(33.79)

Any Drug Use

$-99.32$

(65.04)

Any Smoking During Pregnancy

$-227.83 * * *$

(41.03)

$-228.50 * * *$

(39.06)

Hard Drug Use

$-163.50 * *$

(58.81)

Age, in years

12.74

11.33

13.32

(12.04)

(11.18)

(11.65)

Age Squared

$-.27$

$-.24$

$-.27$

$(0.20)$

(0.19)

$(0.20)$

High School Graduate

$-34.76$

$-32.33$

$-36.21$

(25.16)

(26.80)

(28.58)

Some College (but not graduate)

34.99

(34.29)

35.83

32.89

(37.43)

(36.21)

College Graduate

17.24

16.68

8.83

(49.59)

(49.83)

(49.17)

Medicaid Birth

$-91.81 * *$

$-91.25 * *$

$-90.14 * *$

(37.17)

(38.26)

(37.13)

Hispanic

$-9.98$

(46.13)

$-2.44$

$-5.86$

(47.12)

(47.07)

Non-Hispanic Black

$-160.51 * * *$

(41.15)

$-156.36^{* * *}$

(40.56)

$-160.66^{* * *}$

(40.75)

Other Non-White Non-Hispanic

$-140.93$

$-136.03$

$-134.49$

(94.23)

(94.54)

(94.66)

Immigrant

$74.33^{*}$

(37.67)

64.90

62.76

(37.19)

(37.57)

Lived with Both Parents at Age 15

$-19.81$

$-21.93$

$-22.19$

(26.71)

(28.18) 
Table 5 (cont'd)

\begin{tabular}{lccc}
\hline & Self-Reported & Any Drug Use & Hard Drug Use \\
\cline { 2 - 4 } & \multicolumn{3}{c}{$\begin{array}{c}\text { Coefficient } \\
\text { (Standard Error) }\end{array}$} \\
\cline { 2 - 4 } $\begin{array}{l}\text { Attends Religious Services Several } \\
\text { Times/Month }\end{array}$ & -.64 & .25 & 1.37 \\
First Birth & $(18.74)$ & $(18.00)$ & $(17.97)$ \\
& $-94.25^{*}$ & $-87.98^{*}$ & $-88.08^{*}$ \\
Number of Pregnancies & $(45.99)$ & $(46.20)$ & $(47.20)$ \\
& 12.09 & 14.02 & 14.25 \\
& $(54.23)$ & $(52.62)$ & $(54.40)$
\end{tabular}

\section{Father Characteristics}

High School Graduate

$-4.84$

(32.33)

39.93

(34.43)

$-6.67$

(61.88)

$60.49^{*}$

(33.64)

$-2.25$

(2.59)

mother)

\section{Child Characteristic}

Male

\section{Parents' Relationship}

Mother Knew Father 12 Months Prior to

Conception

5.54

(51.97)

2.44

(52.53)

Married at Time of Conception

74.43*

(38.58)

$\mathrm{R}^{2}$

.09

1988

$73.55^{*}$

(38.19)

.09

1988

$97.45^{* * *}$

$97.54 * * *$

(18.92)

40.14

(34.84)

$-5.27$

(61.14)

56.69

(34.61)

$-1.83$

(2.38)

$(2.35)$

(18.92)

1.69

(52.10)

71.74*

(37.19)

.09

1988

*** significant at $1 \%$ level; $* *$ significant at $5 \%$ level; * significant at $10 \%$ level 
Appendix Table 1(a): Bivariate probit estimates of the effects of prenatal drug use on low birth weight $(\mathrm{N}=1988)$

\begin{tabular}{ccc} 
Self-Reported & Any Drug Use & Hard Drug Use \\
\hline & Coefficient & \\
& [Marginal Effect] & \\
& (Standard Error) & \\
\hline
\end{tabular}

\section{Mother Characteristics}

Self-Reported Drug Use

Self-Reported Smoking

Any Drug Use

Hard Drug Use

Age, in years

$-.03$

$[-.00]$

(0.06)

.00

Age Squared

[.00]

$(0.00)$

High School Graduate

Some College (but not graduate)

College Graduate

Medicaid Birth

Hispanic
$-.00$

$[-.00]$

(0.09)

$-.15^{*}$

[-.02]

(0.09)

$-.03$

[-.00]

(0.19)

$.35^{* * *}$

[.05]

(0.11)

$-.16$

[-.02]

$(0.12)$
$-.02$

[-.00]

(0.05)

[-.00]

(0.06)

.00

[.00]

$(0.00)$

.00

[.00]

(0.00)

$-.00$

.02

[-.00]

[.00]

(0.10)

(0.10)

$-.14 *$

[-.02]

(0.08)

$-.02$

[-.00]

$(0.22)$

$-.12$

[-.02]

$(0.08)$

.02

[.00]

(0.22)

$.35 * * *$

[.05]

(0.11)

$34 * * *$

[.05]

(0.11)

$-.17$

[-.02]

$-.16$

[-.02]

(0.12) 
Non-Hispanic Black

Other Non-White Non-Hispanic

Immigrant

Lived with Both Parents at Age 15

Attends Religious Services Several Times/Month

First Birth

Number of Pregnancies

\section{Father Characteristics}

High School Graduate

Some College (but not graduate)

College Graduate

High School or More

\begin{tabular}{cc} 
Self-Reported & Any Drug Use \\
\hline Coefficient \\
{$[$ Marginal Effect $]$} \\
(Standard Error)
\end{tabular}

.13

[.02]

(0.10)

.16

[.03]

$(0.22)$

$-.04$

[-.01]

$(0.12)$

$-.09$

[-.01]

(0.07)

$-.10$

[-.01]

$(0.07)$

.18

[.03]

(0.15)

$-.02$

[-.00]

$(0.18)$
.12

[.02]

$(0.11)$

.16

[.03]

$(0.22)$

$-.01$

[-.00]

(0.12)

$-.08$

[-.01]

(0.06)

$-.10$

[-.01]

$(0.07)$

.17

[.03]

(0.15)

$-.03$

[-.00]

$(0.17)$
Hard Drug Use

Hard Drug Use

.12

[.02]

(0.10)

.14

[.02]

$(0.22)$

.01

[.00]

(0.11)

$-.09$

[-.01]

(0.06)

$-.10$

[-.01]

(0.07)

.17

[.03]

(0.15)

$-.03$

[-.00]

$(0.18)$

.13

[.02]

.13

(0.09)

[.02]

08

$(0.09)$

[.01]

(0.12)

.09

[.01]

(0.13)

.11

.11

[.02]

[.02]

$(0.29)$

.11

[.02]

$(0.09)$

Continued on next page 


\begin{tabular}{ccc} 
Self-Reported & Any Drug Use & Hard Drug Use \\
\hline & Coefficient & \\
& [Marginal Effect $]$ & \\
& (Standard Error) &
\end{tabular}

Different Race-Ethnicity Than Mother mother)
$-.28 * *$

[-.04]

$(0.13)$

$.01^{*}$

$[.00]$

$(0.01)$
(Standard Error)
$-.27 * *$

$[-.03]$

$(0.13)$

.01

$[.00]$

$(0.01)$
$-.26^{*}$

$[-.03]$

$(0.13)$

.01

$[.00]$

$(0.01)$

\section{Child Characteristic}

Male

$-.00$

[-.00]

$(0.10)$

$-.02$

$[-.00]$

$-.02$

$(0.09)$

[-.00]

$(0.09)$

Parents' Relationship

Mother Knew Father 12 Months Prior to

$-.10$

[-.01]

$(0.11)$

$-.09$

$-.09$

Conception

[-.01]

(0.10)

$[-.01]$

$-.15$

$[-.02]$

$-.14$

$(0.10)$

Married at Time of Conception

(0.12)

[-.02]

$(0.12)$

$-.13$

$[-.02]$

*** significant at $1 \%$ level; $* *$ significant at $5 \%$ level; * significant at $10 \%$ level 
Appendix Table 1(b): First stage bivariate probit estimates (dependent variable is prenatal drug use)

\begin{tabular}{ccc} 
Self-Reported & Any Drug Use & Hard Drug Use \\
& Coefficient & \\
(Standard Error) & \\
\hline
\end{tabular}

\section{Mother Characteristics}

Self-Reported Smoking

$.65 * * *$

$(0.17)$

Any Smoking During Pregnancy

$.89 * * *$

$.71 * * *$

$(0.14)$

(0.13)

Any Alcohol Use During Pregnancy

$.72 * * *$

$.79 * * *$

$.83 * * *$

(0.13)

(0.14)

(0.15)

Any Future Drug Use

$1.64 * * *$

$1.29 * * *$

$1.18 * * *$

(0.32)

(0.27)

$(0.24)$

Price of Cocaine

$-.06 *$

$-.12 * * *$

$-.11 * * *$

$(0.03)$

(0.04)

(0.03)

Age, in years

.06

$(0.05)$

$-.01$

$.12 * *$

(0.04)

(0.06)

Age Squared

$-.00$

.00

$-.00$

$(0.00)$

(0.00)

$(0.00)$

High School Graduate

$-.31 * * *$

$(0.09)$

$-.04$

$-.22$

$(0.09)$

(0.18)

Some College (but not graduate)

$-.38 * * *$

(0.13)

$-.05$

$-.15$

$(0.15)$

College Graduate

$-.53 * *$

$(0.26)$

$-.58 * * *$

$-1.12 * * *$

$(0.20)$

(0.38)

Medicaid Birth

.06

$(0.14)$

$.24 *$

$.31 *$

$-.21$

$(0.15)$

(0.13)

(0.16)

Hispanic

$-.08$

(0.11)

$-.47 * * *$

Non-Hispanic Black

$.35 * * *$

(0.09)

$.43 * *$

(0.18)

.01

.30

$(0.30)$

.08

(0.11)

Other Non-White Non-Hispanic

Immigrant

$-.27$

$(0.21)$

$(0.39)$

.14

$(0.29)$

$-.68 * * *$

$-.72 * * *$

(0.15)

(0.14)

Lived with Both Parents at Age 15

$-.01$

$(0.07)$

$.15 * *$

(0.06)

.10

$(0.07)$ 


\begin{tabular}{|c|c|c|c|}
\hline & Self-Reported & Any Drug Use & Hard Drug Use \\
\hline & & $\begin{array}{c}\text { Coefficient } \\
\text { (Standard Error) }\end{array}$ & \\
\hline $\begin{array}{l}\text { Attends Religious Services Several } \\
\text { Times/Month }\end{array}$ & $\begin{array}{l}-.31 * * * \\
(0.11)\end{array}$ & $\begin{array}{l}-.16 \\
(0.11)\end{array}$ & $\begin{array}{c}-.02 \\
(0.11)\end{array}$ \\
\hline First Birth & $\begin{array}{l}.19 \\
(0.15)\end{array}$ & $\begin{array}{c}.08 \\
(0.11)\end{array}$ & $\begin{array}{c}.01 \\
(0.19)\end{array}$ \\
\hline Number of Pregnancies & $\begin{array}{l}.19 \\
(0.17)\end{array}$ & $\begin{array}{c}.08 \\
(0.13)\end{array}$ & $\begin{array}{c}.15 \\
(0.21)\end{array}$ \\
\hline Father Characteristics & & & \\
\hline High School Graduate & & $\begin{array}{l}-.12 * * \\
(0.06)\end{array}$ & $\begin{array}{l}-.01 \\
(0.17)\end{array}$ \\
\hline Some College (but not graduate) & & $\begin{array}{l}-.35^{* * *} \\
(0.08)\end{array}$ & $\begin{array}{l}-.51 * * \\
(0.20)\end{array}$ \\
\hline College Graduate & & $\begin{array}{l}-.20 \\
(0.18)\end{array}$ & $\begin{array}{c}.07 \\
(0.24)\end{array}$ \\
\hline High School or More & $\begin{array}{c}-.12 \\
(0.12)\end{array}$ & & \\
\hline Different Race-Ethnicity Than Mother & $\begin{array}{l}.15 \\
(0.11)\end{array}$ & $\begin{array}{l}.12 * \\
(0.08)\end{array}$ & $\begin{array}{l}-.19 \\
(0.15)\end{array}$ \\
\hline $\begin{array}{l}\text { Age Difference in Years (father minus } \\
\text { mother) }\end{array}$ & $\begin{array}{c}.01 \\
(0.01)\end{array}$ & $\begin{array}{c}.01 \\
(0.01)\end{array}$ & $\begin{array}{l}.02 * * * \\
(0.01)\end{array}$ \\
\hline Child Characteristic & & & \\
\hline Male & $\begin{array}{c}.08 \\
(0.12)\end{array}$ & $\begin{array}{l}.18^{* *} \\
(0.08)\end{array}$ & $\begin{array}{l}.18 \\
(0.14)\end{array}$ \\
\hline Parents' Relationship & & & \\
\hline $\begin{array}{l}\text { Mother Knew Father } 12 \text { Months Prior to } \\
\text { Conception }\end{array}$ & $\begin{array}{l}.19^{*} \\
(0.10)\end{array}$ & $\begin{array}{c}.06 \\
(0.13)\end{array}$ & $\begin{array}{l}-.05 \\
(0.18)\end{array}$ \\
\hline Married at Time of Conception & $\begin{array}{l}-.57^{* * *} \\
(0.18)\end{array}$ & $\begin{array}{c}-.24 \\
(0.20)\end{array}$ & $\begin{array}{c}-.22 \\
(0.28)\end{array}$ \\
\hline $\begin{array}{l}\text { Test Results } \\
\text { Chi-Square joint significance test of } \\
\text { instruments } \\
\text { (p-value) }\end{array}$ & $\begin{array}{c}80.81 \\
(.00)\end{array}$ & $\begin{array}{c}56.94 \\
(.00)\end{array}$ & $\begin{array}{c}106.45 \\
(.00)\end{array}$ \\
\hline $\begin{array}{l}\text { Exclusion tests ( } \mathrm{p} \text { values): } \\
\text { Price per gram of cocaine in city } \\
\text { Alcohol use during pregnancy } \\
\text { Any future drug use }\end{array}$ & $\begin{array}{l}.35 \\
.71 \\
.44\end{array}$ & $\begin{array}{l}.29 \\
.85 \\
.76\end{array}$ & $\begin{array}{l}.29 \\
.77 \\
.78\end{array}$ \\
\hline $\begin{array}{l}\text { Wald test of rho }=0 \\
\text { (p-value) }\end{array}$ & $\begin{array}{l}.19 \\
(.67)\end{array}$ & $\begin{array}{l}.00 \\
(.99)\end{array}$ & $\begin{array}{l}.27 \\
(.60)\end{array}$ \\
\hline
\end{tabular}

$* * *$ significant at $1 \%$ level; $* *$ significant at $5 \%$ level; $*$ significant at $10 \%$ level 